\title{
Enhancing Vocabulary Memorization and Retention through LMS and MultiEx Game Platforms among Thai Tertiary Students
}

\author{
Woralak Bancha and Nattapong Tongtep \\ Prince of Songkla University, Phuket, Thailand \\ https:// orcid.org/0000-0002-1005-9079 \\ https://orcid.org/9280-9287-0002-0000
}

\begin{abstract}
Although technology has been integrated into vocabulary instruction, to date, few studies have compared whether learning management system (LMS) vocabulary exercises or vocabulary online games facilitate better vocabulary acquisition. The purpose of this study was to investigate whether the Test of English for International Communication (TOEIC) vocabulary lessons plus LMS exercises and TOEIC vocabulary lessons plus MultiEx games (online games) foster short-term vocabulary memorization and long-term vocabulary retention, as well as which performed better. Participants were 72 firstyear students at a university in southern Thailand. They were divided into two experimental groups, one given LMS exercises and the other MultiEx games. A word list was taken from the TOEIC word list and a pre-test was used to determine how many words students knew. The unknown words were used in the design of the vocabulary lessons. Ten lessons were provided for the students. Immediately after each lesson, a post-test was conducted to measure their vocabulary recognition. Two weeks after the final lesson, a delayed post-test was conducted to determine how many of the new words had been retained. The main finding was that both vocabulary memorization and retention were enhanced through the use of LMS exercises and the use of MultiEx games. The results showed a higher mean score for the MultiEx game group in both the immediate post-tests and the delayed post-test. Although the differences between the two groups were not statistically significant, the findings suggest integrating technology enhances vocabulary learning outcomes.
\end{abstract}

Keywords: learning management system (LMS); long-term retention; online games; short-term memorization 


\section{Introduction}

Vocabulary, as a foundation and a key element of language acquisition, has been the focus of a great deal of English as a foreign language (EFL) research. Inadequate vocabulary knowledge can cause learning difficulties and poor English proficiency (Ocampo \& McNeill, 2019). Despite the awareness of its crucial role, many Thai university students have low levels of vocabulary knowledge, and vocabulary instruction has received little attention compared to other macro skills (Bancha, 2019). Several methods have been employed for improving vocabulary acquisition; however, autonomous learning through mediation by technology such as computer-assisted language learning (CALL) is supported by many scholars (Boulton \& Cobb, 2017; Çakmak et al., 2021; Lin, 2015).

CALL is widely accepted in modern classrooms and is increasingly used in many educational institutions worldwide. CALL is defined as "any process in which a learner uses a computer and, as a result, improves his or her language" (Beatty, 2013, p. 7). Budgets have been allocated for CALL development and teacher training programmes have been conducted. Consequently, CALL has developed rapidly and in a variety of forms, meeting the demands of users in different circumstances and limitations (Beatty, 2013; Derakhshan et al., 2015).

One such form is the learning management system (LMS), which is "software used to plan, implement and evaluate a specific learning process" (Almrashdeh et al., 2011, p. 30). An LMS has been employed in a university in southern Thailand where this study was conducted. These systems provide many educational benefits to both teachers and students as shown in several studies (Han \& Shin, 2016; Kumar et al., 2011). The university encourages its lecturers to utilize the LMS, which is accessible to all staff and students using university accounts.

Even though the LMS meets the demands of teaching and learning activities in general, there are some limitations on its use in language lessons on which this present study focuses. As a result, some teachers incorporate other CALL in their courses, such as teacher tool software packages provided with commercial books. Other teachers use other online software available on the market to facilitate students' language learning. Technologies that appeal to learners can enhance language learning (Nayan \& Krishnasamy 2015; Silsüpür, 2017). This study therefore investigated a new technology designed for language teaching and learning: the MultiEx game.

The MultiEx game is a journey game in which players have to complete several gap-filling tasks along their journey. In order to complete the tasks, players need vocabulary knowledge. All gap-filling tasks are at the sentence level. The tasks in the MultiEx game have been well designed to align with the objectives of the lessons. As a first step in the MultiEx game development, the TOEIC vocabulary lesson was chosen to assess English proficiency. The university has a policy to use the TOEIC as the appropriate test of English proficiency and the university's graduation criteria. Therefore, preparing for the test is crucial, and 
mastering vocabulary will undoubtedly enable students to gain better scores in the TOEIC.

As a teacher of English, the main researcher also created vocabulary exercises on the LMS using the same TOEIC vocabulary to encourage students to selfstudy and enhance vocabulary knowledge anywhere and anytime. The MultiEx game and LMS exercises were used with two different groups of students to compare their achievement in the same lessons using different CALL methods. The results may lead to further development of CALL integration in language classrooms. Furthermore, to the best of our knowledge, few studies have compared the effectiveness of these CALL methods on vocabulary memorization and retention. Therefore, the results of the present study could reduce this gap.

In this study, the TOEIC vocabulary lessons were integrated with two different CALL approaches: LMS exercises and the MultiEx games with the aim of comparing which type of practice better facilitated vocabulary memorization (short term) and retention (long term).

\subsection{Purposes of the Study}

Accordingly, this study aims to:

i) investigate whether the TOEIC vocabulary lessons plus LMS exercises and TOEIC vocabulary lessons plus MultiEx games (online games) foster short-term vocabulary memorization and long-term vocabulary retention; and ii) compare which type of practice better improved vocabulary acquisition.

In order to meet the above objectives, the following research questions are put forward:

i) Which type of TOEIC vocabulary practice promotes better vocabulary memorization - LMS exercises or MultiEx games?

ii) Which type of TOEIC vocabulary practice promotes better vocabulary retention - LMS exercises or MultiEx games?

\section{Literature Review}

\subsection{Computer-assisted Language Learning (CALL)}

Computer-assisted language learning (CALL) is defined as "any process in which a learner uses a computer and, as a result, improves his or her language" (Beatty, 2003, p.7). CALL has been developed into a wide range of applications and language teaching and learning approaches, beginning with the drill-andpractice based programs to the virtual learning environments and mobileassisted language learning (MALL) (Shokrpour et al., 2019). CALL as a technology-mediated language learning tool has shown potential for L2 learning outcomes (Boulton \& Cobb, 2017; Lin, 2015; Milton et al., 2012), including vocabulary development (Çakmak et al., 2021, Kayaaltı, 2018).

CALL research has been conducted to make comparisons between two or three experimental groups or between experimental groups and control groups and then examine the increases in vocabulary scores between pre- and post-tests. For example, Ghorbani and Jahandar (2015) found that CALL improved vocabulary retention in Iranian learners. The findings suggested that CALL provided 
extensive opportunities to learn languages in an amusing atmosphere at a convenient time. Eizadpanah et al. (2014) found that CALL had positive impacts on the vocabulary achievement and long-term memory of intermediate EFL learners. Their study showed that students benefitted from the instruction which encouraged them to learn English. Talarposhti and Pourgharib (2014) found that an experimental group performed significantly better than the other group in a retention test. Their study suggests that the presentation of vocabulary with visual, aural, and sentence contexts in CALL promotes vocabulary retention. In another study by Shokrpour et al. (2019), the experimental group outperformed the control group. The study indicated that the enjoyment and flexibility of learning and practice led to vocabulary learning. Regarding these studies, CALL has enhanced vocabulary acquisition through a number of factors.

Even though CALL offers substantially positive impacts, there is little evidence to support conclusions on the effectiveness of different CALL techniques. For instance, Kaya (2006) found that there are no significant differences in student outcomes between conventional and blended approaches. A study by Son (2001) showed no different effects of electronic glossaries on vocabulary learning and reading comprehension because "the computer-based assistance for delivering the meanings of words in each study was accompanied by different presentation methods" (p.33). Despite these arguments, it is worth noting that applying CALL based on the students' actual needs can optimize the students' motivation in learning English (Çakmak et al., 2021; Shokrpour et al., 2019). Furthermore, the role of technology and its impact on learning differ depending on the population (Plonsky \& Ziegler, 2016).

Apart from the common methodology, underlying technology-mediated theories of L2 vocabulary learning are found to be similar. Handley (2014) reviewed CALL research with young learners from 2000 to 2010 which showed that dual coding theory, spaced learning theory, sociocultural theories, and many reading theories were the major theoretical framework. A systematic review conducted by Yang et al. (2021) found that information or cognitive theories were commonly used in studies for PreK-12 learners published between 2011 and 2020.

Even though numerous CALL studies have been conducted, some research gaps are identified. A theoretical framework was not clearly specified in the studies (Viberg \& Gronlund, 2013; Yang et al., 2021). The systematic review, from 2005 to 2012 by Viberg and Gronlund (2013) and from 2011 to 2020 by Yang et al. (2021), reveals that over 50\% of studies of English language learning did not clearly state the theoretical framework. Furthermore, Macaro et al. (2012) reviewed studies between 2001 and 2010 which showed a lack of relation of their findings to previous studies or theories. Therefore, the theoretical framework and the reasons for its adoption (section 2.2) and relating previous studies or theories (section 4) were clearly articulated in this study.

In this study, LMS and MultiEx games were the two CALL platforms. In terms of LMS and vocabulary acquisition, two previous studies with Indonesian 
university students by Novitasari et al. (2018) and Mustafa et al. (2019) have been identified. Both studies supported the effectiveness of LMS as it motivated students to learn vocabulary. Likewise, many studies demonstrate/confirm? the positive effects of online games on vocabulary learning (DeHaan, 2011; Shabaneh \& Farrah, 2019; Silsüpür, 2017). However, studies of games as a means of instruction in the classroom have returned inconclusive results (DeHaan, 2011). As not much LMS research has been conducted on vocabulary learning and the positive effects of games are not clear cut/definitive?, investigating the effects of LMS and MultiEX games is still worth studying in order to compare which methods of learning lead to better vocabulary acquisition.

\subsection{The Role of Memory in Vocabulary Memorization and Retention}

\subsubsection{Definitions of Memory}

The main literature related to this study concerns memory. Memory involves cognitive and mental processes. Memory is defined as the capacity of taking in information, storing it, and recalling it when time passes/with the passing of time? (Sherwood, 2015). The process of memorizing is analagous to information encoding, storage, and retrieval (Baddeley, 2020). Encoding engages the sensory system to encode information. Once encoded, input or information is subsequently stored. Retrieval involves recalling the code which will be used in a process or activity (Atkinson \& Shiffrin, 1968). Retrieval is not always successful: it depends on the effects of cues and on the type of information.

\subsubsection{Types of memory}

Short-term memory refers to the memory that holds information temporarily (Nee \& Jonides, 2013). Short term memory is related to working memory. According to Baddeley and Hitch (1974), working memory is a multi-component system which can encode auditory and visual information. While researchers (Atkinson \& Shiffrin, 1968) define short-term memory as a single unitary system which can hold only limited amounts of information, other researchers (Baddeley \& Hitch, 1974) argue that working memory is a multi-component system that includes components other than auditory and visual information.

Working memory involves four main parts, namely a central executive, a visuospatial sketchpad, a phonological loop, and an episodic buffer (McLeod, 2017). The central executive is the most important component that enables the systems to function. It selects only attentive information to be processed in the memory (Baddeley, 1966, 2020). The other two main components for the present study include the visuospatial sketchpad and the phonological loop. The visuospatial sketchpad deals with visual and spatial information whereas the phonological loop stores and processes spoken and written information. An articulatory (spoken) code can be encoded directly in the phonological loop. This explains how information is retained through repetition. However, written words can be stored as well if they are converted into an articulatory code. To elaborate, visually presented information can be transformed into phonological codes and stored as words which are silently articulated. The evidence suggests the work of the phonological loop in the effect of phonological similarity: this means that words that share a similar sound are more difficult to remember than those with a different sound (Conrad \& Hull, 1964; Pajak et al., 2016). The 
episodic buffer acts as a temporary store connecting the working memory and long-term memory. Therefore, even though working memory is a subsystem of short-term memory, working memory can retain and process information whereas short-term memory broadly refers to the single system which can hold information only for a short while.

According to Miller (1951), short-term memory can hold approximately seven pieces of information in twenty seconds. This means learners can memorize new items only for a short while. However, there are techniques that can be used to foster better retention, such as chunking and rehearsal (Oberauer, 2019; Souza \& Oberauer, 2018), meaningful contexts (Anderson, 1984), the word length (Bancha, 2004; Jalbert et al., 2011), and homophones (Hanley \& Bakopoulou, 2003; Liu \& Winer, 2020). Furthermore, different sensory channels affect memorization. Double-channel input facilitates memorization better than a single channel. For instance, recalling words only seen (semantic encoding) is more difficult than recalling words seen together with images (semantic and visual encoding). The longer words are stored in working memory, the better they will be maintained in long-term memory (Atkinson \& Shiffrin, 1968).

Long-term memory is a filing system and is the final stage in the memory process. Information that is stored in long-term memory will last longer than that stored in short-term memory; however, it can decay over time (Atkinson \& Shiffrin, 1968). Information may last in short-term memory for seconds only, but can last in long-term memory for years.

There are two major types of long-term memory: implicit and explicit memory. These two types of memory can be further divided into different types, including episodic (events), semantic (meaning of words), declarative (general knowledge) and procedural (how to do things) memory. While the first three types of memory engage explicit memory, the last type is unconscious or implicit memory (McLeod, 2017). Furthermore, recalling information from different types of memory requires different degrees of effort (Tulving, 1972). To enable words to be retained more successfully, words should be repeated, retrieved from time to time, retrieved in different activities, used in various and meaningful contexts, and personalized (Thornbury, 2006).

As with short-term memory, information transferred into long-term memory is encoded in three main ways, namely visual, semantic and acoustic encoding. Stimuli or information encoded in long-term memory lasts for different lengths of time, depending on the way it is encoded and how many times it is noticed and recalled (Atkinson \& Shiffrin, 1968; Baddeley, 1966, 2020). This encoding, noticing and recall is termed rehearsal (Atkinson \& Shiffrin, 1968).

However, Baddeley and Hitch (1974) argue that Atkinson and Shiffrin's rehearsal explanations of long-term memory are too simplistic. They argue that rehearsal does not always promote long-term memory. Information can also be transferred without rehearsal. For instance, some people can recall information that they do not rehearse, and some people cannot recall information even 
though they have read their notes several times. In addition, elaboration rehearsal or meaningful memorizing techniques that involve the use of images, thinking, and associations with words foster better recall (Raaijmakers, 2003). Evidence suggests that factors underpinning successful transfer of information are motivation, learning strategies, and the effects of input provided (McLeod, 2017).

Among several studies of factors facilitating memorization and retention, one of the most influential, conducted by Nation (2013), emphasizes three main factors, namely noticing, retrieval, and creative use. Noticing means paying attention to the words rather than the parts of a message and is very important as learning does not occur without it (Schmidt, 2008). Retrieval takes place after noticing. After words have been learned and comprehended, they should be retrieved during tasks. Retrieval makes a stronger memory link and enables words to be retained in the long-term memory. In addition, creative or generative use engages learners to review and use words in a variety of contexts, thereby facilitating their memorization.

Another learning theory is task-induced involvement load (TIL) (Eckerth \& Tavakoli, 2012; Huang et al., 2012; Soleimani \& Rahmanian, 2015), where the effects of different tasks and conditions on vocabulary learning and retention are studied. The greater the involvement of learners in tasks, the deeper the cognitive processing and the better the retention of vocabulary (Laufer \& Hulstijn, 2001). However, it is worth noting that tasks with high levels of involvement do not always lead to better retention than tasks with low levels of involvement.

Thus, the main theoretical framework underpinning this study is the nature of memorization. Even though the adopted theoretical framework has been used in many CALL studies (Handley, 2014; Yang et al., 2021), the choice of this framework was explicitly articulated to fill the gap identified by Yang et al. (2021).

\section{Method}

\subsection{Research Design and Participants}

This study adopted a quasi-experimental research design (Maciejewski, 2020). A government university in southern Thailand was the setting of the study. A convenience sampling method was adopted to select participants (Creswell, 2014) who were first-year Thai students studying in scientific and language fields. There were 72 students ( 37 female and 35 male) who completed all the tests. They were divided into the two study groups, LMS exercise and MultiEx game. They were considered low proficiency based on mean grade scores in a common previous course of 1.33 out of 4 for the LMS exercise group (35 students) and 1.29 out of 4 for the MultiEx game group (37 students). During the data collection period, they did not take any other English courses which might have affected the results. 


\subsection{Data Collection Instruments}

The study used three main instruments. First, before the study was conducted, students received a vocabulary pre-test to identify their unknown TOEIC words and scores. The TOEIC words used in the study were selected if they appeared in both the TOEIC word list (http:/ / www.newgeneralservicelist.org/toeic-list) and an academic word list. The written test was designed as a simple gap-filling exercise with parts of speech and pronunciation as this met the minimum requirement for word knowledge (Nation, 2013; Thornbury, 2006) and avoided guessing issues. The value of the item-objective congruence (IOC) index for content validity was 1.00, indicating that the validity was high.

The second instrument was the immediate post-tests (IPT). IPTs, consisting of receptive and productive parts, were administered after each lesson. They combined the pre-test format (gap-filling of parts of speech and meanings) with a multiple-choice format to examine students' receptive knowledge (parts of speech and meanings) and productive knowledge (words in use). A native English-speaking teacher checked for grammatical accuracy and three Thai teachers of English checked for content validity (IOC). The IOC scores of all the tests were very close to one (1), indicating high validity of all ten tests. Then the reliability of the multiple-choice tests was confirmed by Cronbach's alpha. All IPTs had a value close to 1 , indicating an acceptable level of reliability.

The third instrument was a delayed post-test (DPT) in which the same ten IPT tests were all administered to both groups on the same day, two weeks after the last IPT. Three hours were allocated for this test; however, most students completed it in approximately two hours.

\subsection{Interventions}

To conduct this quasi-experimental study, three interventions were provided. First, the students' unknown 100 words from the pre-test were adopted to create 10 lessons with 10 words per lesson. Each lesson included the same features of the target words, i.e., functions (parts of speech), L1 (Thai) meanings, L2 (English) definitions, sentence samples and pictures representing the meaning of the words. All the lesson materials were checked by a native English-speaking teacher for grammatical accuracy, and they were uploaded to the LMS.

The second intervention was the MultiEx games. The MultiEx games were researcher-developed games. The games are online instructional video games. They were created as a journey game through a PGR Maker MV and exported as an executable (.exe) file through the Enigma Virtual Box program. Everyone could access the games from a free public platform. The games were provided as vocabulary exercises for students to check whether they could remember the target words and whether they could apply the words in use. After students selfstudied the vocabulary, they could access the link to the game and play it as many times as they liked. However, it is worth noting that this group gained more exposure to the vocabulary before and during the game journey. In the game, they needed to read an incomplete sentence and choose one of the four options to fill in the blank as shown in Image 1. At the end of the game, they could see their score. There were 10 items in a game. 


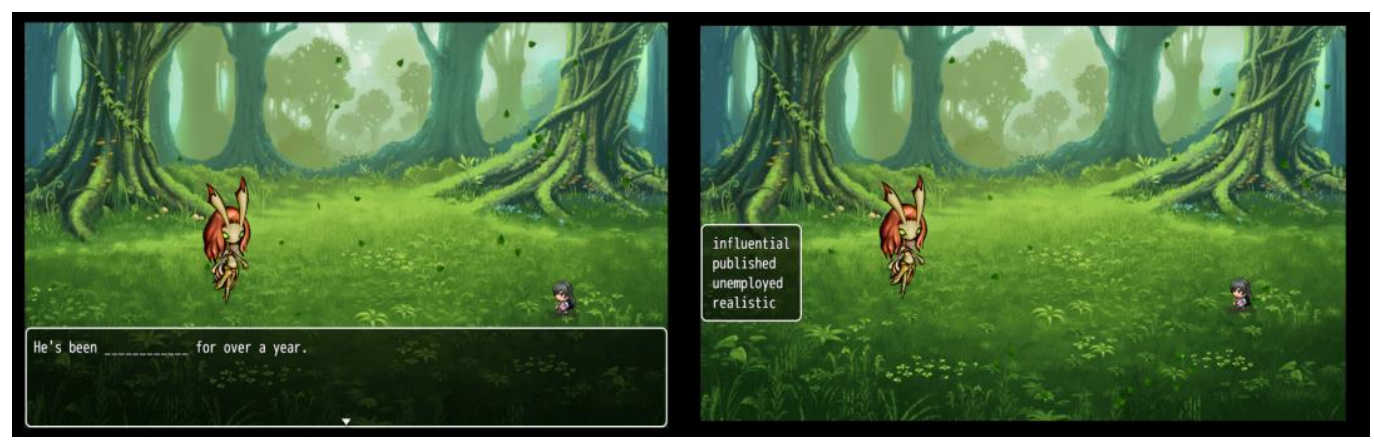

Image 1: Example of MultiEx games

The third intervention was the LMS exercises. The same incomplete sentences (gap-filling) used in the MultiEx games were also used on the LMS exercises. Vocabulary lessons and vocabulary exercises were uploaded to LMS, where students could access them as many times as desired. At the end of the test the exercises provided immediate feedback as shown in Image 2.

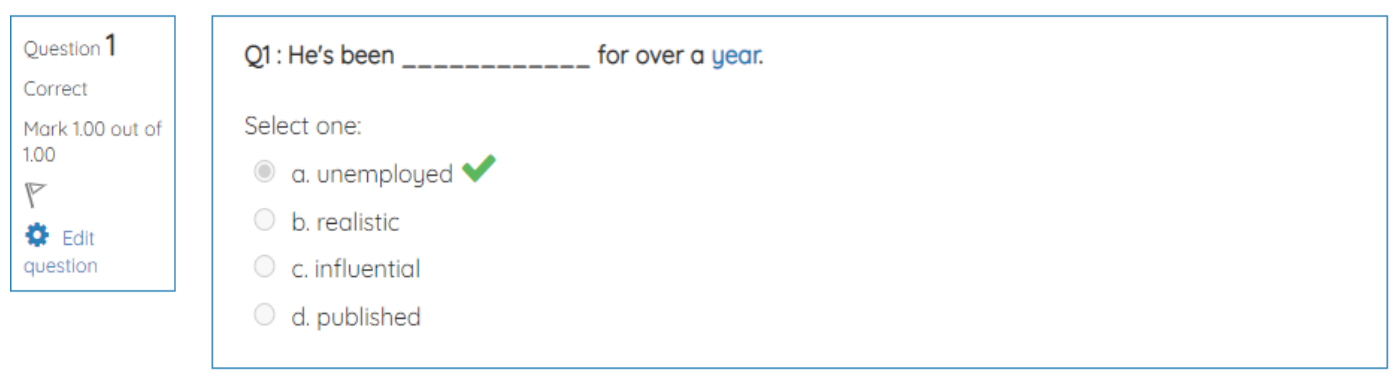

Image 2: Feedback of the correct answers

\subsection{Data Collection Procedures}

Before collecting data, the target words used in the study were selected from the TOEIC word list. Then, all the instruments and procedures were piloted with another group of second-year students to examine the feasibility of the study. After the pilot test, the actual study was conducted. Students were informed of the purposes and procedures of the study and their formal consent to participate was obtained. Students were assigned to groups, and then self-studied one lesson each morning for 10 working days, taking the IPT each day. Two weeks after completion of the ten lessons, both groups took the delayed post-test on the same day during class time.

\subsection{Data Analysis}

This study used the Statistical Program for Social Sciences (SPSS) to analyse numeric data. The T-test was the main statistic used to compare the mean scores of the pre-test, the IPTs and the DPT. To measure short-term vocabulary memorization, an independent sample t-test of IPTs was used to compare the mean scores of two types of practice between these two groups. Then, to measure long-term vocabulary retention, a paired samples t-test was used to analyse the mean scores of the IPTs and DPT within-groups. 


\section{Results and Discussion}

\subsection{Research Question 1: Effectiveness in Terms of Short-Term Memorization}

Table 1 presents the results of the ten immediate post-tests.

Table 1: Comparison of the total mean scores on the IPTs of both groups

\begin{tabular}{|c|c|c|c|c|c|}
\hline Test & Group & Total Score & $\bar{x}$ & $t$ & Sig \\
\hline \multirow{2}{*}{ IPT } & LMS exercises & \multirow{2}{*}{300} & 266.89 & \multirow{2}{*}{-.080} & \multirow[t]{2}{*}{.936} \\
\hline & MultiEx games & & 267.32 & & \\
\hline
\end{tabular}

The findings indicate that the MultiEx game group could gain higher mean scores than the LMS exercise group; however, there was no significant difference $(p<0.05)$. Thus, neither practice method provides a significantly better result in vocabulary memorization. It is possible to argue that the vocabulary lessons offered dual encoding channels. As semantic encoding (meanings) facilitates the best memory (Craik \& Tulving, 1975), dual channels of both semantic (meanings) and visual (pictures) encoding lead to deeper memory processing (Mayer, 2005). Furthermore, L1 translation was an easy vocabulary learning strategy (Schmitt, 2008; Walters \& Bozkurt, 2009). The results support a recent study by Ugla et al. (2019) which found that low-proficiency students utilize L1based strategies. Another possible explanation why scores were high was the opportunity to practise repetitively. The results of this study are consistent with those of Ruegg and Brown (2019) who found that the number of times a word is encountered is important in vocabulary memorization. The following Table 2 presents the mean scores and the statistical significance of each IPT.

Table 2: Comparison of the mean scores on each IPT of both groups

\begin{tabular}{|c|c|c|c|c|c|}
\hline Test & Group & Total Score & $\bar{x}$ & $t$ & Sig \\
\hline \multirow[t]{2}{*}{ IPT 1} & LMS exercises & \multirow{2}{*}{30} & 23.54 & \multirow{2}{*}{-.422} & \multirow{2}{*}{.674} \\
\hline & MultiEx games & & 24.14 & & \\
\hline \multirow{2}{*}{ IPT 2} & LMS exercises & \multirow{2}{*}{30} & 26.11 & \multirow{2}{*}{-.872} & \multirow{2}{*}{.387} \\
\hline & MultiEx games & & 26.97 & & \\
\hline \multirow{2}{*}{ IPT 3} & LMS exercises & \multirow{2}{*}{30} & 26.31 & \multirow{2}{*}{-.252} & \multirow{2}{*}{.802} \\
\hline & MultiEx games & & 26.51 & & \\
\hline \multirow{2}{*}{ IPT 4} & LMS exercises & \multirow{2}{*}{30} & 26.57 & \multirow{2}{*}{-.624} & \multirow{2}{*}{.535} \\
\hline & MultiEx games & & 27.00 & & \\
\hline \multirow{2}{*}{ IPT 5} & LMS exercises & \multirow{2}{*}{30} & 27.60 & \multirow{2}{*}{.577} & \multirow{2}{*}{.566} \\
\hline & MultiEx games & & 27.19 & & \\
\hline \multirow{2}{*}{ IPT 6} & LMS exercises & \multirow{2}{*}{30} & 26.69 & \multirow{2}{*}{-.151} & \multirow{2}{*}{.880} \\
\hline & MultiEx games & & 26.81 & & \\
\hline \multirow{2}{*}{ IPT 7} & LMS exercises & \multirow{2}{*}{30} & 27.20 & \multirow{2}{*}{-1.027} & \multirow{2}{*}{.308} \\
\hline & Multix games & & 27.86 & & \\
\hline \multirow{2}{*}{ IPT 8} & LMS exercises & \multirow{2}{*}{30} & 27.86 & \multirow{2}{*}{1.193} & \multirow{2}{*}{.237} \\
\hline & MultiEx games & & 27.03 & & \\
\hline \multirow{2}{*}{ IPT 9} & LMS exercises & \multirow{2}{*}{30} & 26.91 & \multirow{2}{*}{-.396} & \multirow{2}{*}{694} \\
\hline & MultiEx games & & 27.22 & & \\
\hline IPT 10 & LMS exercises & 30 & 28.09 & 1 & 112 \\
\hline 11110 & MultiEx games & 30 & 26.59 & 1.012 & 1.12 \\
\hline
\end{tabular}

Note. ${ }^{*} p<.05$ 
Table 2 shows that the MultiEx game group gained better mean scores than the LMS exercise group in most vocabulary lessons. However, the results obtained from the independent samples t-test show no statistically significant differences $(p>0.05)$. Therefore, MultiEx games were not significantly better than the LMS exercises in terms of short-term memorization.

It is possible that some other factors, including the time interval and the recency (words encountered last are better remembered than those encountered first), might affect their memorization (Paivio, 1986, 2014). In this current study, students self-studied and then took the IPTs after they had completed each lesson. The frequency of word encounters in the LMS exercises and MultiEx games could facilitate memorization. As the LMS exercises and MultiEx games allowed students to redo the exercises as many times as they liked, it is probable that the more students practised the exercises or games, the better the words were memorized (Hajebi et al., 2018; Laufer \& Osimo, 1991; Ni et al., 2020). Creative or generative use of the new vocabulary items in different contexts enables students to rethink uses for them, facilitating vocabulary memorization (Nation, 2013). The findings of the present study are consistent with those of Ruegg and Brown (2019) who found that the number of times a word is encountered is important for vocabulary retention in long-term memory.

Furthermore, the explanation could be that gap-filling, as a productive vocabulary task requiring students to use their cognitive and language ability to complete the task, fosters vocabulary retention. In other words, the more effort students put into the task, the more likely they are to memorise the words (Huang et al., 2012). The findings of the current study are in accord with those of Kim (2011) whose research shows that when students use their cognitive and language competence to complete a task in a given time, they process the words more deeply and retain them better. Similarly, these findings corroborate the work of Ruegg and Brown (2019) whose findings show that output tasks (requiring students to use their skills) lead to better vocabulary retention than input tasks.

\subsection{Research Question 2: Effectiveness in Terms of Long-Term Retention}

Table 3 presents the mean scores of the IPTs and DPT of both groups to compare the effectiveness in terms of long-term vocabulary retention.

Table 3: Comparison of mean scores on each IPT and the DPT of both groups

\begin{tabular}{|c|c|c|c|c|c|c|c|}
\hline Group & $\mathbf{N}$ & $\begin{array}{l}\text { Total } \\
\text { score }\end{array}$ & $\begin{array}{c}\bar{x} \\
\text { on the } \\
\text { ten IPTs }\end{array}$ & $\begin{array}{c}\bar{x} \\
\text { on the } \\
\text { DPT }\end{array}$ & $\begin{array}{l}\text { Difference } \\
\text { s between } \\
\text { both tests }\end{array}$ & $t$ & Sig \\
\hline LMS exercises & 35 & \multirow{2}{*}{300} & 266.89 & 160.37 & 106.52 & 13.85 & $0.00^{*}$ \\
\hline MultiEx games & 37 & & 267.32 & 164.3 & 103.02 & 13.30 & $0.00^{*}$ \\
\hline
\end{tabular}

Note. ${ }^{*} p<.05$

Table 3 shows that the difference between the mean score of the IPTs and the DPT of the MultiEx game group is smaller than that of the LMS exercise group (103.02 and 106.52 respectively). Data indicates that the practice of MultiEx 
games could facilitate better retention than the practice of LMS exercises. Even though paired sample t-test data show that the mean scores of both groups were significantly different $(\mathrm{p}>0.05)$ or both practice methods could promote vocabulary learning in both short-term and long-term memory, the second group shows better results because of the smaller decrease in the results.

The following Table 4 presents the mean scores of the DPT on each lesson.

Table 4: Comparison of the mean scores on the delayed post-tests of both groups

\begin{tabular}{|c|c|c|c|c|c|}
\hline DPT & Group & $\begin{array}{l}\text { Total } \\
\text { Score }\end{array}$ & $\bar{x}$ & $\mathbf{t}$ & Sig \\
\hline \multirow{2}{*}{ DPT 1} & LMS exercises & \multirow{2}{*}{30} & 19.06 & \multirow{2}{*}{2.607} & \multirow{2}{*}{$.011^{*}$} \\
\hline & MultiEx games & & 16.27 & & \\
\hline \multirow{2}{*}{ DPT 2} & LMS exercises & \multirow{2}{*}{30} & 17.23 & \multirow{2}{*}{-1.993} & \multirow{2}{*}{$.051^{*}$} \\
\hline & MultiEx games & & 19.43 & & \\
\hline \multirow{2}{*}{ DPT 3} & LMS exercises & \multirow{2}{*}{30} & 17.03 & \multirow{2}{*}{-1.100} & \multirow{2}{*}{275} \\
\hline & MultiEx games & & 18.24 & & \\
\hline \multirow{2}{*}{ DPT 4} & LMS exercises & \multirow{2}{*}{30} & 16.31 & \multirow{2}{*}{.321} & \multirow{2}{*}{.749} \\
\hline & MultiEx games & & 15.89 & & \\
\hline \multirow{2}{*}{ DPT 5} & LMS exercises & \multirow{2}{*}{30} & 17.89 & \multirow{2}{*}{.206} & \multirow{2}{*}{.837} \\
\hline & MultiEx games & & 17.62 & & \\
\hline \multirow{2}{*}{ DPT 6} & LMS exercises & \multirow{2}{*}{30} & 16.06 & \multirow{2}{*}{-.702} & \multirow{2}{*}{.485} \\
\hline & MultiEx games & & 16.86 & & \\
\hline \multirow{2}{*}{ DPT 7} & LMS exercises & \multirow{2}{*}{30} & 14.69 & \multirow{2}{*}{-.128} & \multirow{2}{*}{.899} \\
\hline & MultiEx games & & 14.84 & & \\
\hline \multirow{2}{*}{ DPT 8} & LMS exercises & \multirow{2}{*}{30} & 15.26 & \multirow{2}{*}{6.397} & \multirow{2}{*}{$.000^{*}$} \\
\hline & MultiEx games & & 9.43 & & \\
\hline \multirow{2}{*}{ DPT 9} & LMS exercises & \multirow{2}{*}{30} & 13.31 & \multirow{2}{*}{-1.213} & \multirow{2}{*}{.230} \\
\hline & MultiEx games & & 14.81 & & \\
\hline DPT 10 & LMS exercises & 30 & 15.06 & 51 & 570 \\
\hline 01110 & MultiEx games & (3) & 15.72 & - & .070 \\
\hline
\end{tabular}

Note: * means $p$ value $>0.05$.

The findings indicate that, in six of the ten DPTs, the MultiEx game group of students gained higher mean scores than the LMS exercises group. However, the independent samples t-test results showed that most of the mean scores of the DPT did not show statistically significant differences $(p>0.05)$. This suggests that using MultiEx games for vocabulary practice did not help students retain vocabulary any better than the use of LMS exercises for practice.

The higher mean scores in the DPTs of the MutiEx games group could be due to the higher frequency of exposure to target words in this type of practice compared to LMS exercises practice. The LMS exercises only allowed students to see the target words just before beginning their practice, whilst the MultiEx games practice allowed students to see them before starting, and again along the game journey. Students practising via MultiEx games simply had more opportunities to see the target words compared to the LMS exercise group. It has been reported that the more frequently students encounter a word, the better they retain the word (Hoa \& Trang, 2020). This explanation is in line with research by Eckerth and Tavakoli (2012) whose study indicated that frequency of 
exposure and task load involvement affected vocabulary learning and retention positively.

A second possible explanation might be that games increase positive attitudes toward learning. Games are reported to motivate students to learn, enable them to pay longer attention to vocabulary lessons (Saha \& Singh, 2016), and make learning more enjoyable (Derakshan \& Khatir, 2015; Lorenzutti, 2016), which can turn intake into knowledge (Krashen, 1992). In addition, enjoyable games encourage students to play them repeatedly, helping word repetition (Nation, 2013; Turgut \& Irgin, 2009). This explanation is confirmed by Aghlara and Tamjid (2011), DeHaan (2011), Shabaneh and Farrah (2019) and Silsüpür (2017) whose studies indicate that games increase students' vocabulary acquisition by helping to maintain their concentration on the learning activity. Research by Abrams and Walsh (2014) and Pasfield-Neofitou (2014) showed that students who learned vocabulary through games gain better scores than those who followed conventional instruction. It is possible that games lead to high motivation when students enjoy learning vocabulary, which eventually transfers the words they have learned to long-term memory (McLeod, 2017).

The results of the present study confirm the effectiveness of integrating technology with learning activities. However, the statistical results do not show a significant difference between these two vocabulary practice methods. A possible explanation might be the ease and convenience of use. Unlike the LMS practice exercise group, students in the MultiEx game group did not receive immediate feedback. It is possible that some students avoided checking the correct answers which affected their understanding of the exercises. The findings support the previous study by Iten and Petko (2016) which indicated that students' awareness of learning benefits is more important than the feelings of fun. Furthermore, the results are concurrent with those of Park et al. (2012) whose study indicated that ease and convenience of use enhances the effectiveness of online learning.

Besides the learning effects of practice using online games and LMS exercises, the frequency of test taking might facilitate vocabulary memorization and retention. Certainly, the frequency of the immediate post-tests for ten consecutive days resulted in more opportunities for target word encounters and word retrieval. This is consistent with research by Bancha (2012) whose findings showed that the frequency of test taking motivates Thai university students to put more effort into learning vocabulary, which eventually facilitates vocabulary memorisation and retention.

Another explanation may be the effects of the vocabulary lessons which were provided to both groups. As these two groups received the same input of vocabulary lessons, it seems essential to discuss lesson effects. It is known that dual encoding channels in vocabulary lessons promote vocabulary retention (Craik \& Tulving, 1975). In this study, vocabulary lessons provided both semantic encoding (written meanings in L1 and L2) and visual encoding (pictures), facilitating deeper processing (Mayer, 2014) and making the words easier to recall (Paivio, 1986, 2014). The value of using pictures in vocabulary 
lessons is highlighted in a study by Jazuli et al. (2019) that showed how, through pictures, low proficiency Malaysian students improved vocabulary acquisition and had a higher motivation to learn English. In addition, findings of a study by $\mathrm{Ou}$ et al. (2020) revealed that pictures are beneficial and increase vocabulary retention in young learners. Furthermore, L1 translation facilitates ease of understanding (Schmitt, 2008; Walters \& Bozkurt, 2009) which was appropriate for the low-level proficiency students in this study. The findings are in line with the study by Ugla et al. (2019) which indicated that low proficiency students use L1-based strategies to acquire a foreign language. In addition, findings of a study by Nanda (2017) showed that L1 equivalents of the vocabulary items enhanced students' retention of them.

It is worth noting that after grading students' IPTs and DPTs, their mistakes revealed some findings reflecting the effectiveness of the vocabulary lessons and practice using LMS or MultiEx games. One of the students' mistakes was to swap word meanings. An example was taken from the third vocabulary lesson which contained two words with the same initial letter ' $c$ ' and final letters 'fy' (clarify and classify). Some students swapped the meanings of these two words. It is possible to explain that they were confused as they lacked opportunities to practise word spellings (word form) in the vocabulary practice of LMS exercises or MultiEx games. A second type of mistake found related to their background knowledge, which seemed to interfere with new knowledge. To illustrate, some students wrote the meaning of 'public' instead of the target word 'publish' and 'career' instead of 'carrier'. It is possible that they were confused between new and known words because of their similar forms (spelling) and sounds (pronunciation). This type of mistake occurs because of phonological loop effects, where similar sounds cause difficulty for learning and recall (Baddeley, 2020). Another explanation is that they could not remember the meanings of the vocabulary and they simply guessed the answers.

\section{Conclusions}

Technology helps promote self-directed learning and enhances vocabulary learning. The results of this study revealed that the TOEIC vocabulary lessons, with practice through both LMS exercises or online MultiEx games, facilitate vocabulary memorisation and retention, and neither form of practice promotes better memorisation or retention. Both methods make it convenient for students to learn anywhere and anytime, and both may be enjoyable. Productive types of practice also foster deep processing and cognitive involvement, facilitating longterm memorisation.

This study makes theoretical contributions to educational technology focusing on online learning with LMS exercises and MultiEx games in promoting vocabulary acquisition. Unlike previous studies investigating only the effectiveness of games and LMS on vocabulary acquisition, the findings of the present study provide a comparative result of two methods of vocabulary practice. Thus, the study contributes to filling the gap in the research of methods of practising for vocabulary memorisation and retention. 
The results confirm the important roles of dual encoding channels of semantic and visual encoding and the positive roles of technology in terms of ease and convenience of accessibility, thereby fostering vocabulary memorisation and retention. Even though the results did not show statistically significant differences between these two methods of practices, MultiEx games could lead to slightly better retention as a result of the higher frequency of word exposure in games than those of the LMS exercises.

\section{Pedagogical Implications}

The findings of the present study could be useful for material designers and teachers when providing supplementary instructional materials to promote vocabulary learning. Regarding these findings, this study offers some implications for future practice. First, opportunities to practice how target words are spelt should be incorporated in online vocabulary lessons and practice using LMS exercises or MultiEx games. The students' answers in the IPTs and DPT showed that students were confused by similar forms, such as career-carrier and publish-public. Thus, providing opportunities to practise spelling orally, or in writing, could help students better memorise new word forms and avoid confusion of similar word forms.

Second, apart from opportunities to practise spelling, incorporating pronunciation in the online vocabulary lessons and LMS exercises or MultiEx games might help students remember vocabulary better. Some students were confused by the words with the initial letter ' $c$ ' and the final letters ' $f y$ ' as in 'classify' and 'clarify'. The students' answers showed phonological loop effects or difficulties caused by words with similar sounds (Baddeley, 2020). In this study, only one channel of visualization was promoted as they could only see the words and pictures to aid meaning, understanding, and memorisation. If pronunciation practice is added to the online lessons, LMS exercises and MultiEx games, they aid memorisation as the visual and auditory channels are encoded at the same time (Paivio, 1986; Paivio 2014). Providing opportunities to practise the pronunciation of new words should help them recognise word forms better, which may minimise phonological similarity issues in the long term.

Third, vocabulary instruction, practice, and feedback should be combined in the same lesson. Owing to the limitation of MultiEx games, not all of these functions can be offered in the lesson. Ease of use is one of the important factors for successful online learning (Garcia-Cabot et al., 2015; Han \& Shin, 2016) and autonomous learning (Park et al., 2012). Therefore, it is essential to add vocabulary practice and feedback in an online vocabulary lesson. Another option is to design online vocabulary lessons and transform these components into an application for convenient use. Fourth, a variety of exercises through LMS or online games should be provided. To attract and keep/maintain? students' attention in self-study lessons, different types of input are essential. Repeating the same format of practice through LMS exercises or online games might not encourage students to practise repeatedly. Consequently, a variety of exercises could reinforce the input in more interesting ways which would eventually motivate them to learn vocabulary. 


\section{Limitation and Recommendations}

The vocabulary exercises on LMS and MultiEx game did not include spelling and pronunciation features. The more opportunities there are to practice, the better the retention. Further studies may include these two aspects of word knowledge on online platforms to promote deep processing and cognitive involvement for better retention. Furthermore, this study did not investigate students' satisfactions with vocabulary lessons, LMS exercises and MultiEx games. Thus, further studies may include other research instruments, such as surveys, questionnaires, focus group interviews and individual interviews to further improve learning materials and gain an insight into the understanding of the study.

\section{Acknowledgements}

This research was supported by the Faculty of International Studies, Prince of Songkla University. Our thanks also go to all the students who participated in the study.

\section{References}

Abrams, S. S., \& Walsh, S. (2014). Gamified vocabulary. Journal of Adolescent \& Adult Literacy, 58(1), 49-58. https://doi.org/10.1002/jaal.315

Aghlara, L., \& Tamjid, N. H. (2011). The effect of digital games on Iranian children's vocabulary retention in foreign language acquisition. Procedia - Social and Behavioral Sciences, 29, 552-560. https:/ / doi.org/10.1016/j.sbspro.2011.11.275

Almrashdeh, I. A., Sahari, N., Zin, N. A. M., \& Alsmadi, M. (2011). Distance learning management system requirements from students' perspective. Journal of Theoretical \& Applied Information Technology, 24(1), 17-27. http://www.jatit.org/volumes/research-papers/Vol24No1/3Vol24No1.pdf

Atkinson, R. C., \& Shiffrin, R. M. (1968). Human memory: A proposed system and its control processes. In Psychology of Learning and Motivation (pp. 89-195). Academic Press. https:/ / doi.org/10.1016/S0079-7421(08)60422-3

Baddeley, A. D. (2020). Exploring working memory: Selected works of Alan Baddeley. Routledge.

Baddeley, A. D. (1966). The influence of acoustic and semantic similarity on long-term memory for word sequences. The Quarterly Journal of Experimental Psychology, 18(4), 302-309. https:/ / doi.org/10.1080/14640746608400047

Baddeley, A. D., \& Hitch, G. (1974). Working memory. In Psychology of learning and Motivation (Vol. 8, pp. 47-89). Academic Press.

Bancha, W. (2004). The effect of using L2 word-L1 meaning rhyme Sets and L2 word-L1 Meaning rhyme sets plus storytelling on vocabulary remembrance and retention of prathom 4 students at Hat Yai Municipality School 2. (Unpublished Master's dissertation). Prince of Songkla University, Hadyai, Thailand.

Bancha, W. (2012). Effects of using vocabulary quizzes on vocabulary memorization and retention of first year students at the Faculty of International Studies, Prince of Songkla University, Phuket. Journal of International Studies: Prince of Songkla University, $\quad 2(2), \quad 57-68 . \quad$ https://so03.tcithaijo.org/index.php/jis/article/view/246826

Beatty, K. (2013). Teaching \& researching: Computer-assisted language learning. Routledge.

Boulton, A., \& Cobb, T. (2017). Corpus use in language learning: A meta-analysis. Language Learning, 67(2), 348-393. https://doi.org/10.1111/lang.12224 
Çakmak, F., Namaziandost, E., \& Kumar, T. (2021). CALL-enhanced L2 vocabulary learning: using spaced exposure through CALL to enhance L2 vocabulary retention. Education Research International, 2021. https://doi.org/10.1155/2021/5848525

Conrad, R., \& Hull, A. J. (1964). Information, acoustic confusion and memory span. British Journal of Psychology, 55(4), 429-432. https:// doi.org/10.1111/j.20448295.1964.tb00928.x

Craik, F. I., \& Tulving, E. (1975). Depth of processing and the retention of words in episodic memory. Journal of Experimental Psychology: General, 104(3), 268. https:// doi.org/10.1037/0096-3445.104.3.268

Creswell, J. W. (2014). A concise introduction to mixed methods research. Sage Publications.

DeHaan, J. (2011). Teaching and learning English through digital game projects. Digital $\begin{array}{llll}\text { Culture } & \mathcal{E} & \text { Education, } & 3(1),\end{array}$ https://static1.squarespace.com/static/5cf15af7a259990001706378/t/5cf56ef150 58e500016494a3/1559588594004/deHaan+\%28April+2011\%29.pdf

Derakhshan, A., \& Khatir, E. D. (2015). The effects of using games on English vocabulary learning. Journal of Applied Linguistics and Language Research, 2(3), 39-47. http://jallr.ir/index.php/JALLR/article/view/40/pdf_38

Derakhshan, A., Salehi, D., \& Rahimzadeh, M. (2015). Computer-assisted language learning (CALL): Pedagogical pros and cons. International Journal of English Language and Literature Studies, 4(3), 111-120. https://doi.org/10.18488/JOURNAL.23/2015.4.3/23.3.111.120

Eckerth, J., \& Tavakoli, P. (2012). The effects of word exposure frequency and elaboration of word processing on incidental L2 vocabulary acquisition through reading. Language Teaching Research, 16(2), 227-252. https://doi.org/10.1177/1362168811431377

Garcia-Cabot, A., De-Marcos, L., \& Garcia-Lopez, E. (2015). An empirical study on mlearning adaptation: Learning performance and learning contexts. Computers $\mathcal{E}$ Education, 82, 450-459. https://doi.org/10.1016/j.compedu.2014.12.007

Hajebi, M., Taheri, S., Fahandezh, F., \& Salari, H. (2018). The role of web-based language teaching on vocabulary retention of adult pre-intermediate EFL learners. Journal of Language Teaching and Research, 9(2), 372-378. http://dx.doi.org/10.17507/jltr.0902.20

Han, I., \& Shin, W. S. (2016). The use of a mobile learning management system and academic achievement of online students. Computers \& Education, 102, 79-89. https:// doi.org/10.1016/j.compedu.2016.07.003

Handley, Z. (2014). Vocabulary CALL for young ESL/EFL learners: A systematic review of the research evidence. In S. Li \& P. Swanson (Eds.) Engaging Language Learners through Technology Integration: Theory, Applications, and Outcomes, 299-325. IGI Global. https://doi.org/10.4018/978-1-4666-6174-5.ch014

Hoa, T. M., \& Trang, T. T. (2020). Effect of the interactive whiteboard on vocabulary achievement, vocabulary retention and learning attitudes. Anatolian Journal of Education, 5(2), 173-186. https:// doi.org/10.29333/aje.2020.5215a

Huang, S., Willson, V., \& Eslami, Z. (2012). The effects of task involvement load on L2 Incidental vocabulary learning: A meta-analytic study. The Modern Language Journal, 96(4), 544-557. https://doi.org/10.1111/j.1540-4781.2012.01394.x

Iten, N., \& Petko, D. (2016). Learning with serious games: Is fun playing the game a predictor of learning success? British Journal of Educational Technology, 47(1), 151163. https://doi.org/10.1111/bjet.12226 
Jalbert, A., Neath, I., Bireta, T. J., \& Surprenant, A. M. (2011). When does length cause the word length effect? Journal of Experimental Psychology: Learning, Memory, and Cognition, 37(2), 338-353. https://doi.org/10.1037/a0021804

Jazuli, A. J. M., Din, F. F. M., \& Yunus, M. M. (2019). Using pictures in vocabulary teaching for low proficiency primary pupils via PI-VOC. International Journal of Academic Research in Business and Social Sciences, 9(1), 311-319. http://dx.doi.org/10.6007/IJARBSS/v9-i1/5399

Kayaaltı, M. (2018). A literature review on the impact of online games in learning vocabulary. International Journal of Scientific and Research Publications, 8(2), 312317.

Khoshnoud, K., \& Karbalaei, A. R. (2015). The effect of computer assisted language learning (CALL) program on learning vocabulary among EFL left and right hemispheric dominant learners. European Online Journal of Natural and Social Sciences, 4(4), 761.

Kim, Y. (2011). The role of task-induced involvement and learner proficiency in L2 vocabulary acquisition. Language Learning, 61, 100-140. https://doi.org/10.1111/j.1467-9922.2008.00442.x

Krashen, S. (1992). The input hypothesis: An update. In Linguistics and Language Pedagogy: The State of the Art, 409-431.

Kumar, S., Gankotiya, A. K., \& Dutta, K. (2011). A comparative study of Moodle with other elearning systems. [Conference presentation]. 3rd International Conference on Electronics Computer Technology, 5, (pp. 414-41). IEEE. https:// doi.org/10.1109/ICECTECH.2011.5942032

Laufer, B., \& Osimo, H. (1991). Facilitating long-term retention of vocabulary: The second-hand cloze. System, 19(3), 217-224. https://doi.org/10.1016/0346251X(91)90046-R

Lin, H. (2015). Computer-mediated communication (CMC) in L2 oral proficiency development: A meta-analysis. ReCALL, 27(3), 261-287. https:// doi.org/10.1017/S09583440 1400041X

Liu, J., \& Winer, S. (2020). Homophones facilitate lexical development in a second language. System, 102249, 1-16. https://doi.org/10.1016/j.system.2020.102249

Lorenzutti, N. (2016). Vocabulary games: More than just wordplay. English Teaching Forum, 54(4): 2-13. https:/ / files.eric.ed.gov/fulltext/EJ1123192.pdf

Macaro, E., Handley, Z., \& Walter, C. (2012). A systematic review of CALL in English as a second language: Focus on primary and secondary education. Language Teaching, 45(1), 1-43. https://doi.org/10.1017/S0261444811000395

Maciejewski, M. L. (2020). Quasi-experimental design. Biostatistics \& Epidemiology, 4(1), 38-47. https://doi.org/10.1080/24709360.2018.1477468

Mayer, R. E. (2014). The Cambridge Handbook of Multimedia Learning. Cambridge University Press.

McLeod, S. (2017). Multi store model of memory. Simply Psychology. http://www.simplypsychology.org/multi-store.html

Miller, G. A. (1951). Language and communication. https://pure.mpg.de/rest/items/item_2364263/component/file_2364262/cont ent

Milton, J., Jonsen, S., Hirst, S., \& Lindenburn, S. (2012). Foreign language vocabulary development through activities in an online 3D environment. The Language Learning Journal, 40(1), 99-112. https://doi.org/10.1080/09571736.2012.658229

Mustafa, F., Assiry, S. N., Bustari, A., \& Nuryasmin, R. A. (2019). The role of vocabulary E-learning: Comparing the effect of reading skill training with and without vocabulary homework. Teaching English with Technology, 19(2), 21-43. 
Nanda, J. V. (2017). The L1 context embedding method in foreign language vocabulary instruction: A comparative study with the keyword method. https:/ / digitalcommons.cedarville.edu/cgi/viewcontent.cgi?article=1007\&cont ext=linguistics_senior_projects

Nation, I. S. P. (2013). Learning vocabulary in another language. Cambridge UniversityPress.

Nayan, S., \& Krishnasamy, H. N. (2015). A preliminary study on vocabulary learning Strategies used by the students from the Faculty of Accountancy. International Journal of Languages, Literature and Linguistics, 1(1), 10-14. http://www.ijlll.org/vol1/3-X10003.pdf

Nee, D. E., \& Jonides, J. (2013). Trisecting representational states in short-term memory. Frontiers in Human Neuroscience, 7, 796 https://www.ncbi.nlm.nih.gov/pmc/articles/PMC3840432/

Ni, C. K., Jong, B., Dison, M. A., Thomas, S. A., Yunus, M. M., \& Suliman, A. (2020). Enhancing Malaysian primary pupils' vocabulary skills using Pocable Game and Pear Deck. International Journal of Learning, Teaching and Educational Research, 19(6), 145-160. https:// doi.org/10.26803/ijlter.19.6.9

Novitasari, I., Aprianto, E., \& Heriyawati, D. F. (2018). The use of mearning management system on university students' vocabulary mastery. Linguista: Jurnal Ilmiah Bahasa, Sastra, dan Pembelajarannya, 2(2), 72-79.

Oberauer, K. (2019). Is rehearsal an effective maintenance strategy for working memory? Trends in Cognitive Sciences: 23(9), 798-809. https://doi.org/10.1016/j.tics.2019.06.002

Ocampo, R., \& McNeill, A. (2019). The relationship between vocabulary size and reading comprehension performance of 12th Grade Thai EFL learners. Journal of Social Sciences, 29(19), 32-41.

Ou, K. L., Tarng, W., \& Chen, Y. R. (2020). Vocabulary learning through picture-viewing and picture-drawing on tablets. In Information Resources Management Association (Ed.) Mobile Devices in Education: Breakthroughs in Research and Practice (pp. 840-857). IGI Global. https://doi.org/10.4018/978-1-7998-17574.ch049

Paivio, A. (1986). Mental representations: A dual-coding approach. Oxford University Press.

Paivio, A. (2014). Mind and its evolution: A dual coding theoretical approach. Psychology Press.

Pajak, B., Creel, S. C., \& Levy, R. (2016). Difficulty in learning similar-sounding words: A developmental stage or a general property of learning? Journal of Experimental Psychology: Learning, Memory, and Cognition, 42(9), 1377. https://doi.org/10.1037/xlm0000247

Park, S. Y., Nam, M. W., \& Cha, S. B. (2012). University students' behavioral intention to Use mobile learning: Evaluating the technology acceptance model. British Journal of Educational Technology, 43(4), 592-605. https://doi.org/10.1111/j.14678535.2011.01229.x

Pasfield-Neofitou, S. (2014). Language learning and socialization opportunities in game worlds: Trends in first and second language research. Language and Linguistics Compass, 8(7), 271-284. https://doi.org/10.1111/lnc3.12083

Plonsky, L., \& Ziegler, N. (2016). The CALL-SLA interface: Insights from a second-order synthesis. Language Learning \& Technology, 20(2), 17-37.

Raaijmakers, J. G. (2003). Spacing and repetition effects in human memory: Application of the SAM model. Cognitive Science, 27(3), 431-452. https://doi.org/10.1207/s15516709cog2703_5 
Ruegg, R., \& Brown, C. (2019). "Digging deep": Using the task involvement load hypothesis to analyse textbooks for vocabulary learning potential. Lingua Pedagogia, Journal of English Teaching Studies, 1(1), 17-28. https://journal.uny.ac.id/index.php/lingua-pedagogia/article/view/18481

Saha, S., \& Singh, S. (2016). Collaborative learning through language games in ESL classroom. Language in India, 16(10), 180-189. http:/ / www.languageinindia.com/oct2016/skseslgames.pdf

Schmitt, N. (2008). Instructed second language vocabulary learning. Language Teaching Research, 12(3), 329-363. https:/ / doi.org/10.1177/1362168808089921

Shabaneh, Y., \& Farrah, M. (2019). The effect of games on vocabulary retention. Indonesian Journal of Learning and Instruction, 2(01), 79-80. https://doi.org/10.25134/ijli.v2i01.1687

Sherwood, L. (2015). Human physiology: from cells to systems. Cengage Learning.

Shokrpour, N., Mirshekari, Z., \& Moslehi, S. (2019). Learning vocabulary electronically: Does computer assisted language learning (CALL) instruction have any impacts on Iranian Efl learners? Cogent Education, 6(1), 1702827. https:// doi.org/10.1080/2331186X.2019.1702827

Silsüpür, B. (2017). Does using language games affect vocabulary learning in EFL classes? Journal of Foreign Language Education and Technology, 2(1), 83-104. https://www.jflet.com/articles/does-using-language-games-affect-vocabularylearning-in-efl-classes.pdf

Souza, A. S., \& Oberauer, K. (2018). Does articulatory rehearsal help immediate serial recall? Cognitive Psychology, 107, https://doi.org/10.1016/j.cogpsych.2018.09.002

Thornbury, S. (2006). How to teach vocabulary. Pearson Education.

Tulving, E. (1972). Episodic and semantic memory. Organization of memory, 1, 381-403. http://alumni.media.mit.edu/ jorkin/generals/papers/Tulving_memory.pdf

Turgut, Y., \& İrgin, P. (2009). Young learners' language learning via computer games. Procedia - Social and Behavioral Sciences, 1(1), 760-764. https://doi.org/10.1016/j.sbspro.2009.01.135

Ugla, R. L., Abidin, M. J. Z., \& Abdullah, M. N. (2019). The influence of proficiency level on the use and choice of L1/L2 communication strategies used by Iraqi EFL students. International Journal of Evaluation and Research in Education, 8(1), 127137. https:// doi.org/10.11591/ijere.v8.i1.pp127-137

Viberg, O., \& Grönlund, ^̊. (2013). Systematising the field of mobile assisted language learning. International Journal of Mobile and Blended Learning (IJMBL), 5(4), 72-90. https://doi.org/10.4018/ijmbl.2013100105

Walters, J., \& Bozkurt, N. (2009). The effect of keeping vocabulary notebooks on vocabulary acquisition. Language Teaching Research, 13(4), 403-423. https:// doi.org/10.1177/1362168809341509

Yang, X., Kuo, L. J., Eslami, Z. R., \& Moody, S. M. (2021). Theoretical trends of research on technology and L2 vocabulary learning: A systematic review. Journal of Computers in Education, 8, 465-483. https:/ / doi.org/10.1007/s40692-021-00187-8 